\title{
Correction to: Silicic conduits as supersized tuffisites: Clastogenic influences on shifting eruption styles at Cordón Caulle volcano (Chile)
}

C. Ian Schipper ${ }^{1}$ (D) Jonathan M. Castro ${ }^{2} \cdot$ Ben M. Kennedy ${ }^{3} \cdot$ Hugh Tuffen $^{4} \cdot$ Jack Whattam $^{1} \cdot$ Fabian B. Wadsworth ${ }^{5}$. Rebecca Paisley $^{6}$ - Rebecca H. Fitzgerald ${ }^{3}$. Emma Rhodes ${ }^{3,7}$ • Lauren N. Schaefer ${ }^{3,8}$ • Paul A. Ashwell ${ }^{3,9}$. Pablo Forte $^{2,10} \cdot$ Gilles Seropian $^{3} \cdot$ Brent V. Alloway $^{11,12}$

Published online: 19 February 2021

C International Association of Volcanology \& Chemistry of the Earth's Interior 2021

\section{Correction to: Bulletin of Volcanology (2021) 83:11 https://doi.org/10.1007/s00445-020-01432-1}

The original version of this article unfortunately contained a mistake. The presentation of Table 1 was incorrect. The corrected table is given below.

The original article can be found online at https://doi.org/10.1007/ s00445-020-01432-1

C. Ian Schipper

ian.schipper@vuw.ac.nz

1 School of Geography, Environment and Earth Sciences, Victoria University of Wellington, PO Box 600, Wellington 6140, New Zealand

2 Institute of Geosciences, Johannes Gutenberg University, Mainz, Germany

3 Earth and Environment, University of Canterbury, Private Bag, Christchurch 4800, New Zealand

4 Lancaster Environment Centre, Lancaster University, Lancaster LA1 4YQ, UK

5 Department of Earth Sciences, Durham University, Durham DH1 3LE, UK

6 Department of Earth and Planetary Sciences, McGill University, 3450 Rue University, Montreal, Quebec H3A0E8, Canada
7 Department of Earth Sciences, Uppsala University, Uppsala, Sweden

8 U.S. Geological Survey, 1711 Illinois St., Golden, CO 80401, USA

9 Department of Chemical and Physical Sciences, University of Toronto, Mississauga, Ontario L5L, Canada

10 Instituto de Estudios Andinos, UBA-CONICET, Buenos Aires, Argentina

11 School of Environment, The University of Auckland, Private Bag, Auckland 92019, New Zealand

12 Núcleo Milenio Paleoclima, Centro de Estudios del Clima y la Resiliencia, and Departamento de Ciencias Ecológicas, Universidad de Chile, Santiago, Chile 


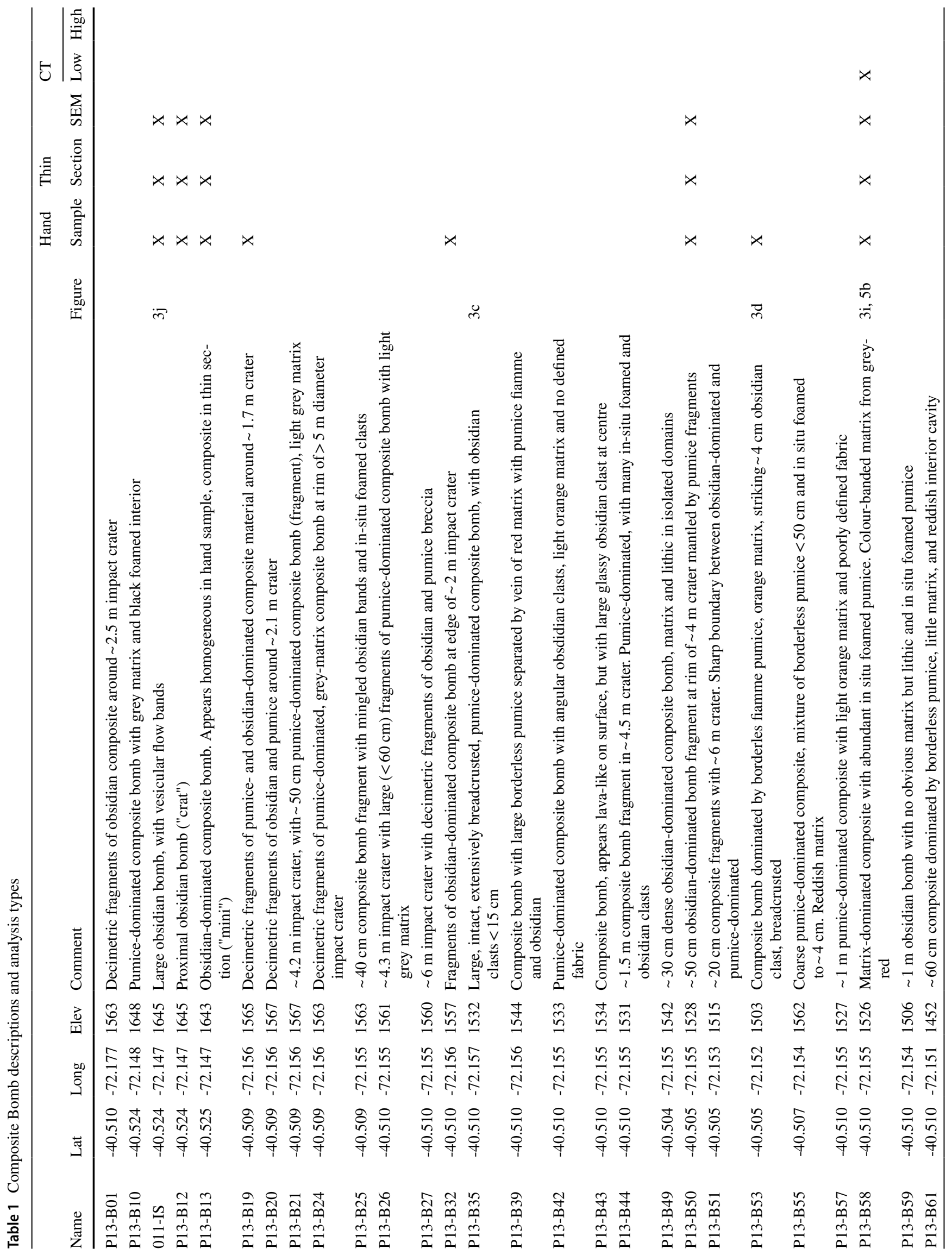




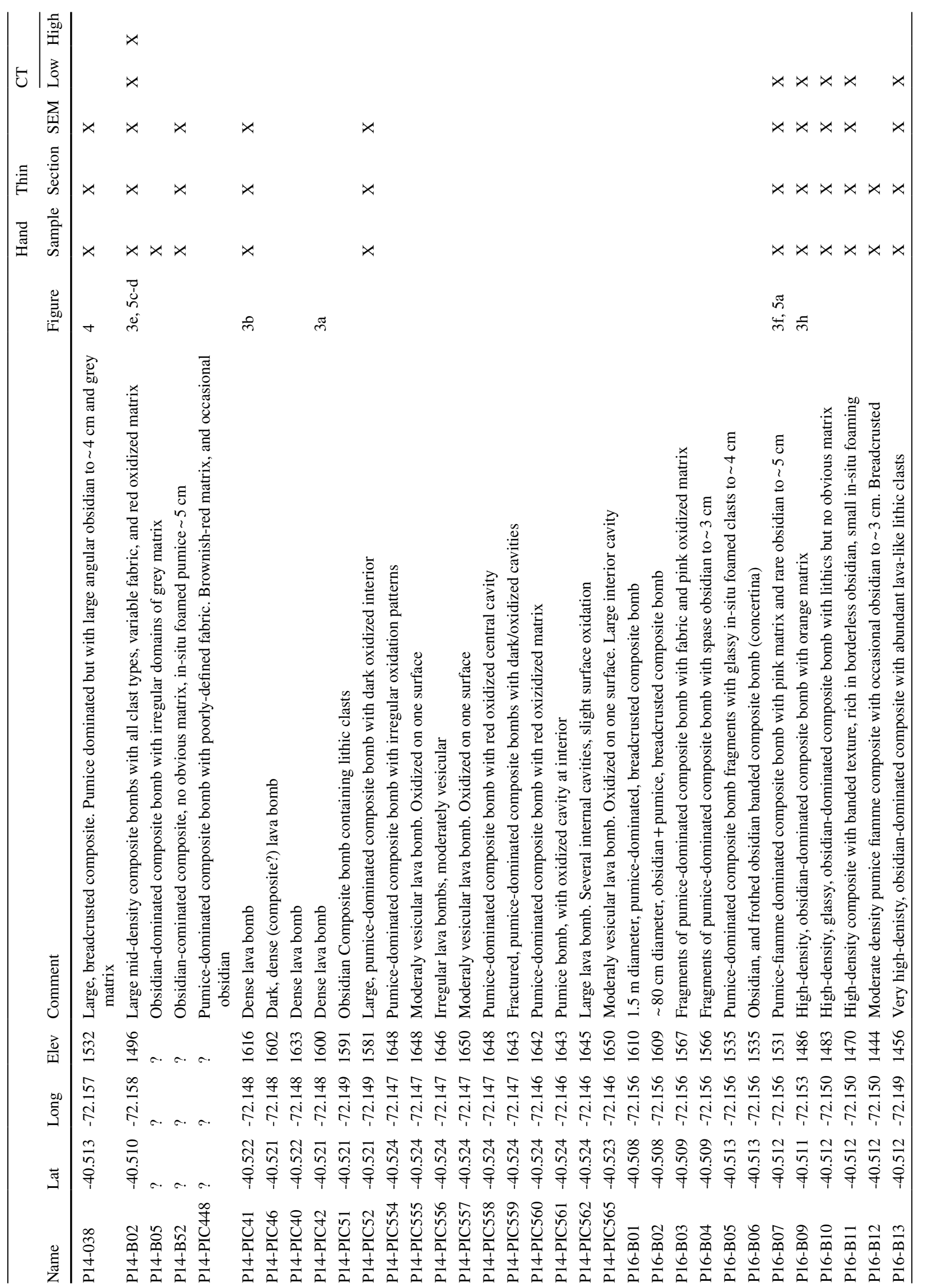




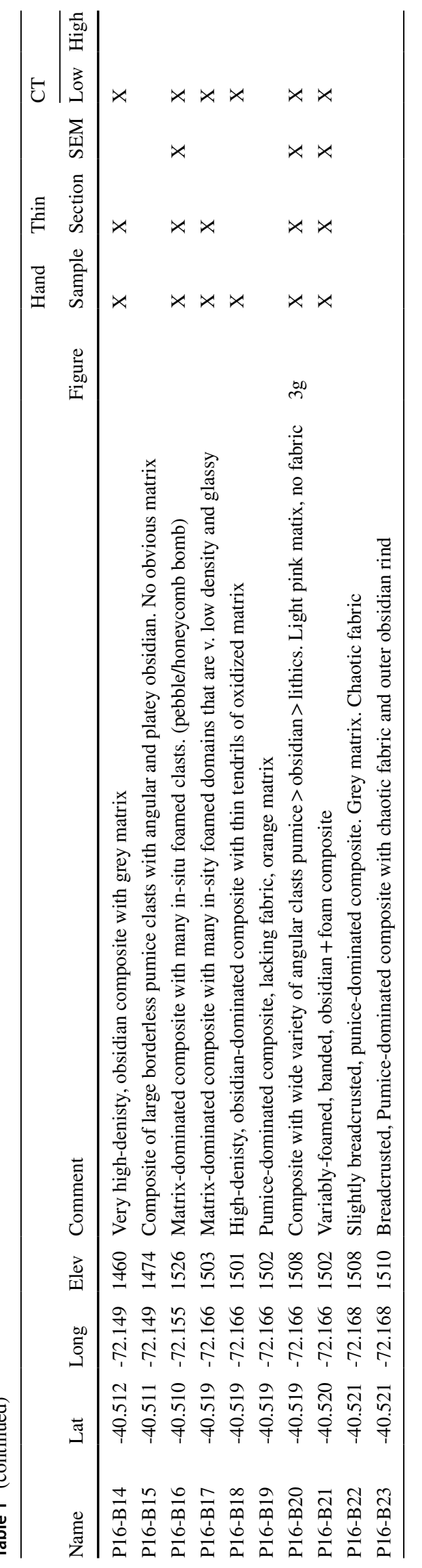

The original article has been corrected.

Publisher's note Springer Nature remains neutral with regard to jurisdictional claims in published maps and institutional affiliations. 